\section{Establishing and facilitating practice-based interprofessional learning: experiences from the TUILIP project}

\author{
Penny J. Furness, ${ }^{1}$ Helen Armitage, ${ }^{1}$ \\ Richard Pitt ${ }^{2}$ \\ 'Sheffield Hallam University, Faculty of \\ Development and Society, Sheffield, UK; \\ 2University of Nottingham, School of \\ Nursing, Midwifery \& Physiotherapy, \\ Nottingham, UK
}

\section{Abstract}

The Trent Universities Interprofessional Learning in Practice (TUILIP) project aimed to establish interprofessional learning (IPL) for healthcare students in clinical practice settings. Ten IPL facilitators were employed in eight varied practice setting pilot sites for up to a year to research, develop and run locally appropriate, sustainable IPL initiatives. Following the pilot phase, a qualitative evaluation was conducted in each site by means of interviews or focus groups with all key stakeholders (facilitators, clinical managers, practitioners, students, service users, carers). Data collection was guided by Kirkpatrick's evaluation framework (1996), which focuses upon participant reactions, and their perceptions of learning, behaviour change and sustainable impact. In keeping with this framework, participants were asked to discuss their experiences of TUILIP in their placement setting (including its facilitation), and their opinions about its impact and success in terms of learning, behaviour change and sustainability. We report a subset of evaluation results relating to the roles of the facilitator, facilitation processes, experiences and challenges, personal and professional impact upon facilitators, and implications for IPL projects in practice. Facilitation tasks included preparing the ground, earning credibility, gathering ideas, researching feasibility, developing initiatives, involving service users, trialling and embedding initiatives. Facilitators were faced with challenges such as getting a focus, time limitations and dealing with logistics. They reported highs (being a fly on the wall, protected time, their educational role, and a sense of satisfaction) and lows (loneliness, frustration and fear of failure), but considered they had developed personally and professionally as a result of their experiences. Results demonstrated the complexity and demands of establishing and facilitating IPL initiatives in practice settings. Facilitation was time-consuming and effortful and did not always achieve its aims, but was a source of satisfaction and personal development. These findings suggest higher education institutions and practice settings should consider carefully the selection, preparation and support for facilitators of practice-based IPL, as well as how to engage local practitioners and service users, and embed changes in the clinical setting.

\section{Introduction}

The importance, benefits and drivers for interprofessional learning (IPL) in the preparation of health professionals, including nurses, are well documented. ${ }^{1}$ Nurses are expected to collaborate and communicate effectively within complex interprofessional teams, and professional bodies (including Nursing and Midwifery Council) expect Higher Education Institutions to provide IPL opportunities for pre-registration students. ${ }^{2}$ Derbyshire and Machin demonstrated that nurses have a positive view of IPL in their training programmes but believe that IPL in clinical practice (rather than academic) settings would enhance understanding and bridge the theory-practice gap. ${ }^{3}$ There are few published reports of IPL in clinical practice as most initiatives occur within the University setting. The Trent Universities Interprofessional Learning In Practice (TUILIP) project aimed to address this deficit by developing sustainable models of IPL in practice by setting up and evaluating IP pilot projects in a range of clinical settings. As well as providing evidence regarding the effectiveness of a variety of initiatives in promoting IP awareness, communication and collaboration among students and practitioners, ${ }^{4}$ the TUILIP evaluation offered insights into the process of creating and delivering IPL interventions.

According to Anderson et al.,$^{5}$ delivering IPE involves facilitation. In dictionary terms, facilitating is the act of making easier or assisting the progress of (from the Collins English Dictionary, 1987). Descriptions and definitions of facilitation in educational literature are wide-ranging and focus primarily upon skill sets, rather than tasks; however a common understanding of facilitation in an IP context is the act of leading an interprofessional group (of students or practitioners) in activities to promote learning with, from and about one another. The TUILIP project defined facilitation more broadly: the roles of facilitators included researching, negotiating and establishing new IPL initiatives as well as the day to day running of IPL activities.

Facilitation competencies and characteristics identified by CAIPE (Centre for the Advancement of Interprofessional Education) include credibility, role modelling, group teaching skills and good humour in face of dif-
Correspondence: Penny J. Furness, Sheffield Hallam University, Faculty of Development and Society, 112, Southbourne Building, Sheffield S10 2BP, UK.

Tel. +44.0114.2252256.501 - +44.0798.4498.688.

E-mail: p.j.furness@shu.ac.uk

Key words: interprofessional education, nursing, clinical practice, evaluation, facilitation.

Acknowledgements: the authors would like to acknowledge the funding grant awarded by Trent Interprofessional Deanery, UK, to support this research, and the hard work and dedication of the ten facilitators whose experiences are reported in this article.

Contributions: PF, TUILIP research fellow, data collection and analysis, article drafting and revising; HA, TUILIP project lead, project conception and design, article revising and final approval; RP, TUILIP project coordinator, project conception and design, article revising and final approval.

Conflicts of interests: the authors declare that there are no potential conflicts of interests.

Received for publication: 27 September 2011. Revision received: 3 January 2012.

Accepted for publication: 9 February 2012.

This work is licensed under a Creative Commons Attribution NonCommercial 3.0 License (CC BYNC 3.0).

(O) Copyright P.J. Furness et al., 2012

Licensee PAGEPress srl, Italy

Nursing Reports 2012; 2:e5

doi:10.4081/nursrep.2012.e5

ficulties ${ }^{6,7}$ Facilitation is central to the success of IPL ${ }^{8}$ and, done well, can change clinical and organisational practice. ${ }^{9}$ It is, however, challenging ${ }^{10}$ and further exploration of the role is needed to ensure IP facilitators are effectively prepared. $^{5}$

\section{Background}

This article considers the roles and experiences of IPL facilitators in eight practice-based initiatives, established under the TUILIP Project. The TUILIP Project was a collaborative venture between Sheffield Hallam University and the University of Nottingham, working with 13 different professional groups and primarily concerned with facilitating IPL in the practice setting for the benefit of learners, service users and carers across a range of practice sites. Pilot sites were chosen to maximise the range of client groups, settings and healthcare professionals, though nurses and nursing students were active in each. These comprised a Stroke Rehabilitation Ward (SR), an Orthopaedic Ward (OW), Acute Mental Health Services (AMH), an Emergency 
Management Unit (EMU), a Learning Disabilities Community Support Service (LD), Hospital Maternity Services (MS), GP Practices (GP) and Women's Health Services (WH). In each site, a facilitator was employed on a part-time basis for up to one year to establish locally appropriate, sustainable IPL activities, ideally with a service-user focus. Beyond developing IPL initiatives for students, engaging staff and involving service users, the remit was deliberately open-ended to allow facilitators to research and develop IPL initiatives most relevant and useful to their practice setting, students and service users.

Facilitators' professional backgrounds included nursing, occupational therapy, social work, teaching, service management and research. Most had other paid roles, which they maintained part-time for the duration of the project and which some resumed afterwards. A total of 10 were employed: individual facilitators in 6 sites; job-share posts in 2 sites. Facilitators were employed for their clinical and educational expertise, their enthusiasm for IPL, and for personal characteristics such as creativity and flexibility. No specific training was given prior to their taking up the facilitation role.

\section{Materials and Methods}

\section{Recruitment}

All key stakeholders were invited to participate in the evaluation, including facilitators, clinical managers, practitioners of various professions at each site, student healthcare professionals, service users and carers. A total of 76 people took part in the evaluation: 10 facilitators; 12 clinical managers; 29 practitioners of various professions; 9 student healthcare professionals; 13 service users and 3 carers. (In addition, 63 facilitator-administered student evaluation forms from 3 sites, appraising specific initiatives, were included).

\section{Data collection}

Participants were interviewed either individually or in focus groups, depending upon their preference and availability (Table 1), although most (50/76) were interviewed alone. Focus groups and most interviews were held in NHS Trust or organisation seminar rooms, although a few participants wished to be interviewed at home or over the telephone. Questions were based upon Kirkpatrick's evaluation framework. ${ }^{11}$ Kirkpatrick's framework was developed over 50 years ago and has been used in various contexts (health, education, business, government, military, and industry). It aims to identify strengths and weaknesses in interventions, and Kirkpatrick stresses that an evaluation should go beyond immediate reactions of the attendees. He considered that evaluative work should be conducted on four different levels: reaction, learning, behaviour, and results/impact. ${ }^{12,13}$

Questions focused upon each of these evaluative areas. Topics included participants' perceptions of the project, descriptions of their involvement, opinions about what had worked well or otherwise, thoughts about the facilitator role, perceptions of what had been learned, and views about the project's sustainability and impact upon practice. NVivo 8 software was used to store, organise and assist in the analysis process. Analysis involved coding and categorising raw data, using constant comparative thematic analysis guided by Kirkpatrick's framework. ${ }^{11}$ Analysis was conducted by the research fellow in the first instance and then discussed with the project lead and coordinator. Results from evaluation of specific sites have been published, ${ }^{4,14}$ and participants received reports from the TUILIP evaluation in their setting, and a final report was prepared and presented to the Strategic Health Authority.

This paper is based upon a subsection of the overall evaluation results. In addition to findings specific to Kirkpatrick's evaluation framework, interviews and focus groups generated considerable data from participants (all stakeholders) in each site regarding facilitation roles, processes and experiences which transcended individual site evaluations, did not fit well with the evaluation framework and merited separate analysis. These data were analysed for key themes using a process of comparative analysis, resulting in three facilitation-focused themes: Facilitator Tasks; Organisational Challenges; and Personal Impacts. Although much of the dataset relating to these theme derived from facilitator interviews, other participants often commented and offered their perspectives upon the facilitator roles, tasks and challenges. Thus findings are based upon the entire participant group, although facilitator voices are dominant.

\section{Ethical approval and ethical issues}

Ethical approvals for the evaluation project were obtained from NHS Research Ethics Committee. Pilot sites were agreed through consultation with NHS Trust and organisational managers, staff were informed and educated about the TUILIP project and its aims, and ethical permissions were sought and granted from each NHS Trust or Organisational R\&D office. Potential participants (those who had involvement in some form with the TUILIP project at each pilot site) were contacted by the researcher by letter or email, provided with an information sheet and invited to respond directly to the researcher if interested. Each participant signed a consent form to participate and for audio-recording of their interview. Interviews and focus group recordings were transcribed, following which sound files were deleted from the recorder. Resulting files were anonymised and held in password-protected computer files, accessible only to the researcher. In reports, mention of specific NHS Trust names was omitted and verbatim

Table 1. Participation in focus groups and interviews by pilot site.

\begin{tabular}{|c|c|c|c|}
\hline Pilot site & Participants & Focus groups & Interviews \\
\hline $\begin{array}{l}\text { Stroke rehabilitation } \\
\text { ward (SR) }\end{array}$ & $\begin{array}{c}14 \\
(13)^{*}\end{array}$ & $\begin{array}{l}1 \text { FG with practitioners/ } \\
\qquad(\mathrm{n}=8)\end{array}$ & $\begin{array}{c}\text { 6: } 1 \text { facilitator; } \\
2 \text { managers; } \\
2 \text { service users; } 1 \text { carer. }\end{array}$ \\
\hline Orthopaedic ward (OW) & 9 & $\begin{array}{l}1 \mathrm{FG} \text { with practitioners } \\
(\mathrm{n}=5)\end{array}$ & $\begin{array}{l}\text { 4: } 1 \text { facilitator; } 1 \text { student; } \\
\text { 1 manager; } 1 \text { service user }\end{array}$ \\
\hline $\begin{array}{l}\text { Acute mental health } \\
\text { Services (AMH) }\end{array}$ & $\begin{array}{c}10 \\
(29)^{*}\end{array}$ & $\begin{array}{l}1 \mathrm{FG} \text { with service users } \\
\qquad(\mathrm{n}=4)\end{array}$ & $\begin{array}{l}\text { 6: } 2 \text { facilitators; } 1 \text { student; } \\
2 \text { practitioners; } 1 \text { manager }\end{array}$ \\
\hline $\begin{array}{l}\text { Emergency management } \\
\text { unit (EMU) }\end{array}$ & $\begin{array}{c}8 \\
(21)^{*}\end{array}$ & 0 & $\begin{array}{l}\text { 8: } 1 \text { facilitator; } 1 \text { student; } \\
5 \text { practitioners; } 1 \text { manager }\end{array}$ \\
\hline $\begin{array}{l}\text { Learning disabilities community } \\
\text { support service (LD) }\end{array}$ & 17 & $\begin{array}{c}1 \mathrm{FG} \text { with service users (4), } \\
\text { supported by carers from } \\
\text { organisation }\end{array}$ & $\begin{array}{c}13: 2 \text { facilitators; } \\
2 \text { students; } 5 \text { practitioners; } \\
2 \text { managers; } \\
2 \text { service user parents. }\end{array}$ \\
\hline Hospital maternity services (MS) & 9 & $\begin{array}{l}1 \mathrm{FG} \text { with practitioners } \\
(\mathrm{n}=5)\end{array}$ & $\begin{array}{c}\text { 4: } 1 \text { facilitator; } 1 \text { manager; } \\
2 \text { service users. }\end{array}$ \\
\hline GP practices (GP) & 4 & 0 & $\begin{array}{c}\text { 4: } 1 \text { facilitator; } \\
1 \text { practitioner; } 2 \text { lead GPs. }\end{array}$ \\
\hline Women's health services (WH) & 5 & 0 & $\begin{array}{l}\text { 5: } 1 \text { facilitator; } \\
2 \text { practitioners; } \\
2 \text { managers. }\end{array}$ \\
\hline Total & $\begin{array}{c}76 \\
(63)^{*}\end{array}$ & 26 & 50 \\
\hline
\end{tabular}

"Non-bracketed figure refers to number of participants interviewed individually or in focus groups. Bracketed figure is the number of student evaluation forms also collected in these pilot sites, which were included within the evaluation dataset. 
extracts were classified only by participants' roles (i.e. student, service user, practitioner) to avoid as far as possible their identification by readers. Participants were offered an anonymised copy of their transcript to keep and check for accuracy (no amendments were requested).

\section{Results}

\section{Theme 1: facilitator tasks}

The facilitation process was complex and comprised several key tasks: preparing the ground, earning credibility, gathering ideas, researching feasibility, developing initiatives, involving service users, trialling and embedding initiatives.

\section{Preparing the ground and earning credibility}

Project leads consulted service managers and practitioners prior to each pilot, however facilitators needed to continue this introductory process by identifying, meeting with, informing and engaging practitioners and managers likely to be influential: the role was about being a salesman and getting the people involved to buy into the product. It is almost a nurturing process [...] you can't force the change. You have to show them what the benefits are of the change are going to be (facilitator, $\mathrm{OW}$ ).

The process of selling IPL, engaging staff interest and encouraging change proved timeconsuming and problematic, especially for facilitators employed from outside the setting, such that project outcomes proved disappointing in some cases. Some met with scepticism and resistance from busy practitioners, which were difficult to overcome. One facilitator described his efforts to earn staff trust and support: you need to establish your own credibility in practice, integrate yourself into the team. I found this difficult at first. The hospital and the ward were a very tight team: they had worked together for many, many years. It was very difficult as an outsider at first getting myself accepted as a member of the team. It took me about the first two months to do this. I was an unknown entity [...]. I had to put change on the backburner and get myself accepted first. You could argue it might have been better if I had been a member of the team in the first place. I worked my socks off trying to get myself accepted (facilitator, $\mathrm{OW}$ ).

\section{Gathering ideas and researching feasibility}

All facilitators judged it vital to gather ideas from staff to ensure initiatives would reflect local needs and priorities, and enjoy greater ownership by and support of local practition- ers, thereby maximising the effectiveness and sustainability of initiatives. For those with little prior knowledge of the area, this process proved long-winded: to get hold of people, get people booked in diaries, and all that kind of thing does take a lot longer than you anticipate (facilitator, WH).

After networking, facilitators had to decide which ideas to pursue by exploring in detail their logistical and practical potential in the real world. At this stage, in most sites, of the whole host of ideas, almost all of them hit a brick wall (facilitator, MS). This caused frustration but was essential if facilitators' interventions were to work in that setting and be sustainable, long term.

\section{Developing initiatives}

Facilitators took different approaches: some encouraged others to develop activities or designed materials for others to use; others took a hands-on approach to both developing and running activities. Evaluation results suggested the hands-off approach was less successful than facilitators who, following consultations, had taken responsibility for driving, developing and running initiatives. One reason for this was practitioners' time constraints: what they wanted was for me to come up with something that I could set up and sort out and they could then run with it (facilitator, MS).

You've got to have somebody to drive it, to motivate, and do the coordinating and pull people together, and look at those opportunities [...] because most people haven't got time in their day jobs to take on that (practitioner, MS).

Facilitators employed from within the setting were quicker to get their ideas off the ground. They had a better initial understanding of what would work locally, had established contacts and had already considered what they wished to achieve, even if the how needed further clarification: I had quite a clear idea of what I wanted to achieve when I started. [...] I wanted to set up some sort of forum, a virtual MDT, of students to look at clinical practice issues and learn from each other and about each other through that process to the betterment of the outcome for the patient. [...] I had no idea how I was going to do that, but I had that in mind. That was the prototype - or the blueprint - for the integrated learning into practice, the ILIP group, which it subsequently became (facilitator, $\mathrm{AMH}$ ).

Initiatives developed across the eight sites included the virtual MDT (multi-disciplinary team) described above, where IP groups of students spoke with service users and made decisions about care based upon service user composite scenarios. There were service user-led IP discussion groups, IP teaching sessions, service user videos as learning tools, and IPLfocused workbooks or activities for students to complete individually or in groups.

\section{Involving service users}

Although an important part of the remit, involving service users proved difficult. Some facilitators were sufficiently challenged simply engaging practitioners and maintaining interest. In two sites, service users were either consulted about initiatives or participated in developing learning tools. In two further sites, however, service users were an integral part of researching, planning and running the IPL initiatives: ${ }^{4}$ successful service user involvement was clearly both challenging but extremely satisfying for facilitators.

\section{Trialling and embedding initiatives}

Most (but not all) ran initiatives at least once during the pilot, and a few had time to evaluate and improve them for subsequent occasions. Running the initiatives, despite planning, was a process of problem-shooting, smoothing the way and responding to constructive criticism: we were very flexible, we took risks [...], we tried to do things and then reflect back on them to see if they worked and whether we could improve them. And really it was an on-going process of improvement. I look back now and think, to some extent, we achieved that. We listened to what people had to say in terms of feedback that we got, and modified what we were doing according to what people wanted (facilitator, LD).

Those who had been able to establish initiatives which were running well and positively evaluated then endeavoured to ensure the sustainability of their successful IPL activities, which meant identifying a champion. In some sites, it had not been possible to develop initiatives for somebody to take forward. In others, facilitators had created extremely successful initiatives and were employed by and remaining within the site post-TUILIP. Here facilitators were motivated - and in one case, funded by the organisation - to sustain their efforts. However, without devoted time and resources, this proved a challenge: the downside is that we've not been able to put as much energy into this since (facilitator, AMH). In the other four sites, local practitioners had taken on facilitators' initiatives and continued to use and develop them, supported in most cases by additional funding from TUILIP for time or resources, as suggested by each setting.

\section{Theme 2: organisational challenges}

Issues, which challenged facilitator success in achieving their aims, included getting $a$ focus, time constraints and dealing with logistics.

\section{Getting a focus}

TUILIP's remit was deliberately broad to encourage flexibility in meeting the varying demands of different settings, service users 
and professionals. Getting a focus meant facilitators first gaining an understanding for themselves of TUILIP's applicability to their setting, a challenge that proved easier for facilitator pairs: the TUILIP project is so different from site to site and there was no blueprint, nothing to work from. We had a blank canvas and in those situations, you need somebody consistently to work it through with and bounce ideas off; because of that partnership, we were able to do that (facilitator, $\mathrm{LD}$ ).

Second, facilitators had to translate and communicate the project to others. Unfortunately, the broad remit was interpreted by practitioners as vague (various pilots), a perception some facilitators found it difficult to overcome: even after I'd been there a year, they were still asking, what are you trying to achieve? (facilitator, GP)

Getting a focus also meant selecting one or two of the many possible initiatives. Some targeted their efforts upon a single idea. Others tried to respond to many practitioner suggestions by developing numerous IPL products, one of whom commented perhaps I could have been more assertive in keeping the direction more focused (facilitator, EMU). Typically the most successful sites focused on one key initiative or found success in only one of a range of initiatives.

\section{Time constraints}

Time was a predominant issue for all facilitators. There were limitations on their own time, either through juggling TUILIP and other roles, or more often because one year proved insufficient for the task. Practitioners and students were also time-limited for clinical or curricular reasons, and clinical work naturally took priority. The year passed very quickly for facilitators, often with a sense that things weren't moving quickly enough: most felt time was too short to properly meet their brief: it would have been nice to have had another six months. I expect every facilitator has said that. It's amazing how long it takes, that was a major shock to me (facilitator, WH).

\section{Dealing with logistics}

Logistical issues, such as student timetabling (of different student groups); staff shift-work patterns, sickness and mobility; and organisational protocols and bureaucracy, created delays for all facilitators. One facilitator, for example, wished to erect a notice-board within a hospital Trust to advertise learning opportunities but was unable during the pilot phase to establish agreement for this. Another found that unusual levels of absence impeded progress with staff engagement: there were seven maternity leaves on the ward, so quite a few of those key people, that I initially met [...] left, so it was almost like starting again in some respect. [...] and they were also undergoing a regrading at the time. It's all the reality of working life so it's not unusual, it's just that from a project point of view and the timescales we had, it was a bit stop-start, really (facilitator, $\mathrm{WH})$.

As indicated here, a number of initiatives were impacted by change and uncertainty within the setting or service, which increased logistical barriers and reduced motivation among practitioners.

\section{Theme 3: personal impacts}

While developing initiatives, facilitators reported both low and high points and revealed how their experiences led to personal and professional development.

\section{Low points: loneliness, frustration, fear of failure}

Facilitators employed singly to work in an unfamiliar setting sometimes found the task a lonely one. One facilitator described herself as A lone voice in a big Trust (EMU), which contrasted with the experience of those working in pairs or in settings with which they were familiar.

Facilitators approached their role with great enthusiasm and, aware of the potential of IPL, were keen to make an impact; however, progress was slow, support was variable, and logistical issues hindered progress and attendance. One facilitator described these times as a lesson in frustration (facilitator, MS), and other evaluation participants were aware that the role was not straightforward: I thought that her main challenge, and her main role, was going to be altering the mindset of everybody that was involved in it. I remember thinking to myself, well, I'm glad I've not got to take that on, cause it seemed huge. I wondered how much she would be able to achieve in the time, and quite quickly realised it would probably be not a lot (practitioner, EMU).

The slow progress and time limitation meant some facilitators, especially those employed from outside an area who had spent months trying to meet relevant individuals, gather and focus ideas, felt pressured in the later months, fearful of the possibility that their efforts would come to nothing: there's the underlying feeling that, god, at the end of this, I could walk away and do nothing, I will have left nothing, and then I would have felt absolutely terrible. If it hadn't have worked, it would have been awful; if I hadn't created anything, I would've felt I'd taken the money under false pretences! (facilitator, MS)

\section{Highs points: new insights, pleasure, satisfaction}

Although most facilitators experienced low points, all reported compensatory highs. One commented: there was nothing I didn't enjoy; I enjoyed the role completely (facilitator, $\mathrm{AMH}$ ).
Although facilitators employed from outside a setting often had a tough job, there were positive aspects to this experience. These included the opportunity to look at a service with $a$ fresh pair of eyes (facilitator, WH), exposure to new experiences and practices, and greater understanding with some concrete evidence of aspects of healthcare outside the facilitators' usual professional remit (facilitator, GP).

Facilitators valued having paid, devoted time for an interesting project with the potential to improve training and change practice. They enjoyed the educational aspects of the role, working with students and practitioners, and witnessing the potential for IPL: the students loved it. The positives that came out of the sessions, the students interacting together it was fantastic (facilitator, $\mathrm{OW}$ ).

Most experienced a sense of achievement when they completed their task and saw initiatives were benefitting students and service users: I think for me, it's taking something that isn't up and running, something that doesn't exist, and then creating it into something that seems quite plausible, that seems as though it can really work. So it's taking it from start to finish, a project, I really enjoyed that (facilitator, MS).

To see the service users feeling valued, it's fantastic - what better feedback is there than that, cause that's what it's all about (facilitator, LD).

\section{Personal and professional development}

Even where projects had enjoyed limited success, facilitators reported increased confidence and new skills, such as strategic planning, project management and teaching. Some mentioned enhanced employment prospects or had taken on new challenging posts in lecturing and public health development. Those who had returned to previous roles believed new insights would enhance their professional practice: there are quite a few things I'd be keen to change to get the staff to work more interprofessionally. [...] So I am looking at my own team quite differently, clinically (facilitator, WH).

\section{Discussion}

The TUILIP evaluation provided insights into the tasks, challenges and rewards of establishing and facilitating IPL in practice settings. IP-focused educational initiatives are challenging because they differ from traditional profession-specific student placement training, so are not easily facilitated within settings where uni-professional education is the norm. Organisational, professional and personal barriers are exacerbated by logistic difficulties, for example, in getting students and profes- 
sionals from different groups together at the same time and in the same place. There is as yet little in the literature with which to make direct comparisons, as few practice-based IPL projects have been reported. Furthermore, although there is some guidance about IPL facilitation, there is agreement among IPL researchers that better understanding of the role is required in order to properly prepare and support facilitators. ${ }^{1,10}$

The experiences reported here demonstrate the complexity of facilitation. Freeth et al. ${ }^{6}$ and Hughes ${ }^{7}$ propose that facilitators need a range of personal, interpersonal and intellectual attributes. This is supported by the evidence from this evaluation of the tasks and challenges inherent in attempting to establish sustainable IPL initiatives in practice. Communication skills and perseverance were required in order to make initial contact with and engage the interest of relevant parties. Research, decision-making, prioritisation and negotiation abilities were needed to identify possible initiatives and explore their potential in the setting. Determination, hard work and organisational, teaching, facilitation and problem-solving skills assisted facilitators when trialling and embedding their initiatives.

The evaluation suggested all parties were surprised by how arduous and time-consuming were the various stages of the change-making process. Introducing IPL in academic settings can be challenging, ${ }^{15}$ but time constraints, local change, support and logistical issues in these clinical settings limited what could be achieved, resulting in considerable pressure and, in some cases, disappointment. Other practice-based IPL studies have also encountered a variety of barriers and delays. ${ }^{16,17}$ The role of facilitators was to change educational practice, bringing the broad and ambitious TUILIP remit to, in many cases, virgin soil for IPL (with its implied criticism of established practice)..$^{18}$ This makes it perhaps unsurprising that, despite the comparative luxury of paid IPL time, not all were able to fulfil the remit. Reeves et al. ${ }^{19}$ discuss the process of change management and note that high-level support is vital to effect change. Managers in each setting were supportive of TUILIP but this evaluation demonstrates the importance of engagement at all levels of an organisation.

In contrast, several facilitators successfully met the TUILIP brief, involving service users and developing exciting IPL initiatives, which seemed well embedded in their practice arena. Employing practitioners - nurses, occupational therapists, social workers - already engaged with the setting, rather than outsiders, was particularly successful, thanks to pre-existing local knowledge, contacts and credibility. ${ }^{20}$ Facilitator pairs worked well since they could discuss issues and problems, support one another, and make reduced demands upon busy local practitioners. Not only were insiders and facilitator pairs more objectively successful, they identified greater rewards and fewer frustrations, suggesting they enjoyed the process more.

Despite its challenges, facilitating IPL had long-term positive effects upon these 10 individuals. Many came away with a great sense of satisfaction and had learned valuable lessons to take into their professional roles. Some took on new jobs, for which they had previously considered themselves under-qualified. The TUILIP journey increased facilitators' confidence in project management, enhanced existing skills and improved employability. In most sites, although not reported here in detail, initiatives continued to be utilised and appreciated by practitioners, students and service users. ${ }^{4}$ Despite limitations, TUILIP was valuable both in making real change to IP learning and working in practice settings, and in exploring the facilitation process.

\section{Limitations}

One limitation of the study was that themes relating to facilitation per se were not the main focus of the TUILIP evaluation, but arose clearly within the data. Therefore, although strong findings in this area emerged, had this been a primary aim, themes may have differed, would likely have been more saturated, and participants more broadly represented. For example, the students who were interviewed made few comments about facilitation, but instead focused upon their experiences and learning, results of which are reported in more detail elsewhere. ${ }^{4}$ In addition, response to the evaluation varied considerably, with some pilot evaluations being based upon only a few respondents, whose views may not have represented others within their pilot. However, practitioners and facilitators were very frank with their opinions, and the authors have tried to present a balanced view.

Data collection and analysis were conducted by a researcher (PF) independent of the TUILIP management and steering teams. Steps were taken to maximise objectivity: interview recordings were transcribed verbatim and participants, offered interview transcripts and the opportunity to identify errors. As with any research study, bias may have been introduced in the way that questions were asked, responses followed up, data analysed and selected for presentation, based upon the researcher's background as a health professional, academic and researcher, her personal interest in interprofessional learning, and her relationship with the project team. Efforts were made, however, to represent all views fairly and to avoid bias.

\section{Conclusions}

Nurses are well placed to perform a pivotal role in IPL, given their central position in the MDT, close contact with patients and relatives, and the number of nursing students relative to other professions. We believe lessons from TUILIP can inform nurses, academics and healthcare professionals wishing to develop practice-based (and service-user focused) IPL initiatives. We suggest that higher education institutions and practice settings should work collaboratively to ensure practitioners are informed and engaged. The setting, timing, duration, remit and scope of IPL should be carefully considered: for example, practice settings undergoing change and upheaval may find it difficult to take on new ideas and initiatives, and protocols and red-tape may impede change within larger organisations. Developing and embedding IPL may take longer than expected, and research / decisionmaking processes may be eased by providing evidence-based examples of good practice, rather than a completely blank canvas. Other considerations include facilitator characteristics, training (e.g. in change management; also see Anderson et al. ${ }^{5}$ who describe an IPL training program) and support, especially given evidence of the difficulties and personal impacts of the role. Inherent challenges can be eased (especially for outsiders) by building in familiarisation time, identifying local contacts and some means of ongoing support and debriefing for that person. Furthermore, local IPL champions may help sustain initiatives long-term.

\section{References}

1. World Health Organisation. Framework for action on interprofessional education and collaborative practice. Geneva: Health Professions Network Nursing \& Midwifery Office / WHO Press; 2010.

2. Nursing and Midwifery Council (NMC). Standards to support learning and assessment in practice: NMC standards for mentors, practice teachers and teachers. Edinburgh: NMC; 2006.

3. Derbyshire JA, Machin AI. Learning to work collaboratively: nurses' views of their pre-registration interprofessional education and its impact on practice. Nurse Educ Pract 2011;11:239-44.

4. Furness PJ, Armitage H, Pitt R. An evaluation of practice-based interprofessional education initiatives involving service users. J Interprof Care 2011;25:46-52.

5. Anderson ES, Cox D, Thorpe LN. Preparation of educators involved in interprofessional education. J Interprof Care 2009;23: 
81-94.

6. Freeth D, Hammick M, Reeves S, et al. Effective interprofessional education, development, delivery and evaluation. Oxford: Blackwell/CAIPE; 2005.

7. Hughes L. Creating an interprofessional workforce: An education and training framework for health and social care in England. London: Dept. of Health/CAIPE; 2007.

8. Barr H. End and means in interprofessional education: towards a typology. Educ Health 1996;9:341-52.

9. Loftus-Hills A, Harvey G. A review of the role of facilitators in changing professional health care practice. Oxford: RCN Institute; 2000.

10. Bjorke G, Haave N. Crossing boundaries: Implementing an interprofessional module into uniprofessional Bachelor programmes. J Interprof Care 2006;20:641-53.

11. Kirkpatrick DL. Great ideas revisited. Train Dev J 1996;50:54-9.
12. Kirkpatrick DL. Evaluating training programs: the four levels. San Francisco: Berrett-Koehler; 1998.

13. Kirkpatrick J, Kirkpatrick W. The Kirkpatrick four levels: a fresh look after 50 years, 1959-2009. April 2009. Available form: http://www.cedma-europe.org/news letter\%20articles/misc/The\%20Kirkpatrick \%20Four\%20Levels\%20-\%20A\%20Fresh \%20Look\%20After\%2050\%20Years\%20(Apr \%2009).pdf

14. Jinks A, Armitage H, Pitt R. A qualitative evaluation of an interprofessional learning project. Learn Health Soc Care 2009; 8:263-71.

15. Guest C, Smith L, Bradshaw M, Hardcastle W. Facilitating interprofessional learning for medical and nursing students in clinical practice. Learn Health Soc Care 2002; 1:132-8.

16. Falconer J, Roth E, Sutin J, et al. The critical path method in stroke rehabilitation: Lessons from an experiment in cost con- tainment and outcome improvement. Quart Rev B 1993;19:8-16.

17. Jackson A, Bluteau P. At first it's like shifting sands: Setting up interprofessional learning within a secondary care setting. $\mathrm{J}$ Interprof Care 2007;21:351-3.

18. Oadansan I, Reeves S. Key elements for interprofessional education. Part 1: The learner, the educator and the learning context. J Interprof Care 2005;19 Suppl 1:2138.

19. Reeves S, Freeth D, Glen S, et al. Delivering practice-based interprofessional education to community mental health teams: understanding some key lessons. Nurse Educ Prac 2006;6:246-53.

20. Morrell C, Harvey G, Kitson A. The reality of practitioner based quality improvement - a review of the use of the dynamic standard setting system in the NHS of the 1990s. Report 14. Oxford: National Institute for Nursing; 1995. 